\title{
Title
}

\section{Reflective Practice in community development: A grounded analysis}

\author{
Authors \\ Juan Manuel Moreno ${ }^{1}$, Kaliat Ammu Sanyal ${ }^{1}$, Firooz Firoozmand ${ }^{1}$, Pauline Rutter ${ }^{1}$, Professor Marie K. \\ Harder $^{1,2^{*}}$ \\ ${ }^{1}$ Values and Sustainability Research Group, School of Computing, Engineering and Mathematics, University of \\ Brighton, Moulsecoomb, Brighton, BN2 4GJ, UK. E-mail: juan_m_moreno@outlook.com; \\ k.sanyal@brighton.ac.uk; f.firoozmand@brighton.ac.uk; p.rutter@brighton.ac.uk; m.k.harder@brighton.ac.uk \\ ${ }^{2}$ Fudan Tyndall Center, Department of Environmental Science and Engineering, Fudan University, 220 Handan \\ Road, Shanghai, 200433, China. E-mail: m.k.harder@brighton.ac.uk

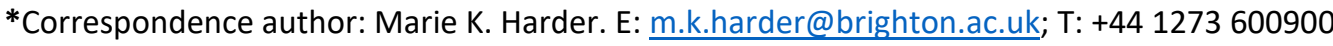




\section{Acknowledgments}

The authors would also like to thank the Community University Partnership Program at the University of Brighton for their help in reaching the community organizations that participated in this study. This research also benefitted from invaluable comments and input from Dr Mary Darking (University of Brighton) and Prof Lori M. Noguchi (Hong Kong University) and to Ms Elona Hoover (University of Brighton) for their invaluable advice on the relevance and literature focus of the research as well as comments on the research approach and methodology. Finally, this research would not have been possible without the participation and active collaboration of the participant community organizations, and our gratitude goes to them. 


\section{Authors contributions}

Juan M. Moreno, K. Ammu Sanyal and Marie K. Harder conceived the idea for the paper; J.M.M. and K.A.S. contributed to the design of the research; M.K.H. and Firooz Firoozmand. identified the case studies, while F.F. and Pauline Rutter prepared the materials and resources and compiled the process documentation of the case-study workshops; F.F. and P.R. carried out the data collection; J.M.M. and K.A.S. led on the conceptual framework, and J.M.M. carried out the data analysis, the situating and linking of the work to other literatures, and the writing of the paper; J.M.M., K.A.S., and M.K.H. contributed to clarifying the focus and general structure of the paper as well as its relevance and methodological approach; all authors worked together on improvements to the paper. 


\section{Declaration of interests}

All authors have approved the final version of the article. The authors declare no conflict of interest. 


\title{
Title
}

\section{Reflective Practices in community development: A grounded}

analysis.

\author{
Abbreviations \\ CD - Community Development \\ $\mathrm{CO}-$ Community Organizations \\ ELC - Experiential Learning Cycle \\ ESDinds - Education for Sustainable Development indicators \\ ID - International Development \\ LGBT\&Q - Lesbian, Gay, Bisexual, Trans and Queer \\ PAR - Participatory Action Research \\ CO-A_Pt\#1, etc. - Civil Society Organization A, participant number 1 \\ RPs - Reflective Practices
}

Stg1, 2, 3 - Elicitation, trigger-statements, mapping and clustering stages of the WV workshop

WB - World Bank

WV - WeValue project 


\section{Abstract}

Reflective practices (RPs) have been recognized as fundamental for the successful and ongoing conception, development, implementation and improvement of community-based development. Despite acknowledgement by development scholars and practitioners that RPs are needed, the ways in which reflection can take place within Community Development (CD) contexts remains under-examined.

In this exploratory study, the authors conduct a grounded thematic analysis of a values-based elicitation and articulation approach with three UK community organizations in order to: (i) identify specific elements in the processes of reflection; (ii) explore how identified themes relate to existing theories and concepts within the RP literature, and how these might provide useful insights to CD contexts; (iii) explore the ways in which values-based elicitation approaches can facilitate RP in CD.

In their analysis, the authors identify four main themes: Reasoning (justification, articulation, recall), Active listening (expansion, replication), Collective articulation (semantic cooperation, semantic negotiations, semantic disagreements), and Tension (confusion, resistance). The findings show that the process of reflection is complex, multi-dimensional and non-linear, highlighting implications for connecting individual and collective reflection within formal and informal processes. Furthermore, the themes relate to concepts of 'experiential learning' and 'awareness' from RP literature, while drawing attention to more active practices and skills needed for RP in CD contexts such as reasoning, listening, and working with tensions within groups. Finally, the research provides important insights on the role of the facilitator in RP within CD contexts, and identifies challenges and opportunities for improvement and further research.

\section{Keywords:}

Europe; UK; Reflective Practices; Processes; Values-based approaches; Community Development 


\section{Introduction}

Recent changes in International Development (ID) policy have shown a trend towards more participatory approaches through community-driven projects and the decentralization of resources and authority to local governments and groups (Mansuri \& Rao, 2013b, pp. 283-284). Yet, while these changes signal positive efforts towards more relevant and inclusive development work, much of the development literature still emphasizes 'outcomes' over 'processes' (Moreno et al., 2017). Moreover, development scholars and practitioners often assume that in the context of community development (CD) projects any given 'groups of people' will de-facto share the same ethical values or always work together towards a common goal. In their World Bank review report of over 500 participation development projects, Mansuri and Rao conclude: "Rarely is much thought explicitly given to the possibility of civil society failure - the possibility that communities, however constituted, may also face significant problems of coordination, asymmetric information, and inequality, which may limit their ability to respond to and resolve market and government failures" (Mansuri \& Rao, 2013b, p. 285).

The 2013 WB report further highlights the lack of serious in-depth ethnographic studies, more localized, relevant and adaptable monitoring and evaluation systems, as well as the urgent need for good qualitative studies in ID that both examine the processes involved in CD efforts and provide clearer understandings of the context where CD projects take place (Ibid, pp. 283-307). By context it is meant not only the local histories, geographies and political factors but also, and above all, the nature of social interactions within groups that directly influence the processes and outcomes, or lack thereof, of any given CD project (Ibid).

Within the context of more participatory approaches to $\mathrm{CD}$, reflective practices (RPs) are known to play a fundamental role; community projects and initiatives involve complex interactions between those involved, as well as processes of iterative reflection through which values, behaviors, perceptions and knowledges are formed, exchanged and negotiated in order to create emergent structures and spaces for action and social change (Moreno et al., 2017, p. 134). 
However, the actual processes involved in RPs and their connection to CD have been seldom examined. An exception, perhaps, is the work of Moore (2002) which draws on Schön's (1983: 1991) seminal work on 'reflection-in-action'. Moore interviews development practitioners from various countries in order to examine the motivations and drives of their practices, concluding that underpinning their field experience, implicit practice-based theories and everyday practices there is a fundamental process of reflection whereby practitioners take the 'necessary time to stop, look around, think about, and reflect on activities, critical analysis, and inquiries of themselves and others in the community regarding community change' (Moore, 2002, p. 31). Nevertheless, the link between RPs and community projects has not been sufficiently examined within the CD literature. There is still a need for research on the effectiveness of different approaches to reflection (Gardner, 2014, p. 18): what kinds of community development practices facilitate reflective practices to take place? In what conditions? What interactions or processes should be facilitated or paid attention to?

This is in fact a serious gap in international and community development scholarship since much of the work carried out in community projects and initiatives involves the conception, development and implementation of community-based activities and engagements through which different actors come together to connect ideas, share knowledge, learn and develop a language of trust and mutual understanding, and work towards effecting positive social change (Facer \& Pahl, 2017, p. 1). These interactions form part of a 'collective process of learning in action for social change', in which learning is not merely about transferring knowledge but also a "creative co-discovery and co-creation of knowledge through collective critical reflection' (Clarke \& Oswald, 2010, pp. 1, 10).

In this paper, the authors contribute to the understanding of RPs in the context of CD projects through an exploratory case-study that examines the processes of reflection taking place during values-based elicitation workshops with three community organizations. The values-based approaches workshop format used is an established approach to assist members of groups to articulate their shared values through interactive sharing and negotiating of the meaning of their group actions. In this way, within the boundaries of this exploratory case-study, the authors could:

(i) Identify specific elements in the processes of reflection; 
(ii) Explore how themes and sub-themes identified relate to existing theories and concepts within the RP literature, and how these might provide useful insights to CD contexts;

(iii) Explore the ways in which values-based elicitation approaches might open spaces of reflection.

These questions are important to development scholars and practitioners for at least three main reasons. Firstly, understanding these processes is essential within CD contexts, where a lot of the work is carried out through collaborations and partnerships (Clarke \& Oswald, 2010; Visser, 2010). The efficiency of projects and initiatives depends as much on understanding local contexts and realities, as on the development of mutual understanding and a language of trust between and within organizations, and amongst stakeholders at the different levels of the process.

Secondly, examining and understanding how processes of collaboration and mutual understandings are reached and how they are articulated is important to help develop more relevant and localized development practices, something that has been recognized as fundamental within the ID community (James, 2010; Mansuri \& Rao 2013b). In this sense, examining the processes of reflection that take place during these negotiations can help make CD projects and initiatives more relevant and meaningful to the contexts in which they take place. Equally important, it may shed some light on what happens when collaboration is not achieved or entirely successful, and how this is dealt with by and amongst the actors involved.

Thirdly, and as it is explained in more detail below, the use of a values-based elicitation and articulation approach offers the possibility to open spaces of trust and mutual understanding. It is also an opportunity to capture those patterns of behavior and relationships present between the individual and group levels, and the factors that shape them.

\subsection{Outline of the paper}

To answer these questions, in section 2 the authors, following a brief review the literature and the importance of RPs within $\mathrm{CD}$, introduce some of the main theories and approaches to RPs and how these might relate or contribute towards community projects. Section 2 ends with the authors setting 
out the known reasons for and opportunities expected for examining processes of RPs through a valuesbased elicitation approach. Section 3 presents the case-study community organizations and describes in detail the methodology used for the research. The findings of the research are presented in section 4 and their implication for current and future research discussed in section 5. The main points and contributions of the paper and opportunities for further research and collaboration are brought together in the conclusion.

\section{A brief review of Reflective Practice}

\subsection{RPs and development studies}

RPs have been studied and applied through by a wide range of disciplines and professional practices such as health, social care and communities of practice contexts (Garrison, 2015, pp. 12, 14), organizational development (Cameron \& Quinn, 2011), education, service learning and youth development (Moely et al., 2009), political and social science circles (Cornwall \& Coelho, 2007; Gaventa, 2006, 2011; Gaventa \& Barrett, 2010; Millner, 2013), and linguistics and psycho-sociology (Chevalier \& Buckles, 2013).

While RPs have not been theorized as extensively within development studies as in some of the above disciplines, development scholars have acknowledged the importance to them for CD work consistently, though not always explicitly (Aragón \& Giles Macedo, 2010; Neely, 2015; Ramalingam, 2013; Visser, 2010). Clarke and Oswald (2010), for example, highlight the central role of 'collective critical reflection' in processes of co-creation of knowledge and action present during community-based activities and interventions. Moore, on the other hand, uses RPs as a tool to examine the motivations and drives of development practitioners when engaging in community work (2002). Others have argued that enhancing critical reflection may help increase communities' ownership of projects by making them more sustainable, relevant and meaningful (Aragón \& Giles Macedo, 2010; Eade, 2007; Kenny \& Clarke, 2010). 
The important role of RPs and need for reflection within the development literature is neither a surprise nor a new phenomenon. On the one hand, the shift in ID programs and interventions in recent years highlight a trend from government-centered and donor-led interventions towards more localized and inclusive community-based programs and initiatives (Mansuri \& Rao, 2013a, 2013b; Miller, 2010). While this fundamental change has been, and still is, the subject of much criticism and skepticism from development scholars (Craig, 2010; Ife, 2010; James, 2010), the main motivation behind it has been the desire to make $\mathrm{CD}$ projects more relevant, meaningful and sustainable to the communities they are addressed to by, first, improving local governance and institutional capacity (Mansuri \& Rao, 2013b), and, second, encouraging and supporting communities' capacities to self-organize, participate and determine their own priorities and needs (Eade, 2007).

On the other hand, the emergence and development of multiple and varied participatory and inclusive approaches to community projects and ID related studies has boosted opportunities for more inclusive and collaborative research. In community capacity-building projects, for example, the increasing role and application of participatory action research (PAR) approaches have allowed academics and practitioners to develop more inclusive, reflective and iterative processes of 'collaborative inquiry' and 'progressive problem-solving' (Burns, 2014; Facer \& Pahl, 2017; McNiff, 2013). Here, PAR approaches have become a fundamental platform for development scholars and workers to take into account local understandings and priorities, change preconceptions and adapt their actions accordingly, and apply reflection practices to gain greater understanding and awareness of their own practices (Chevalier \& Buckles, 2013). Scholars of complex adaptive systems and theorists in systems thinking have also emphasized how processes of iterative reflection and consultation can potentially increase the understanding of different perspectives and priorities of actors at the different levels of a community project and their interdependencies (Aragón \& Giles Macedo, 2010; Fowler \& Ubels, 2010; Kenny \& Clarke, 2010; Visser, 2010). Finally, evaluation capacity-building studies have used RP and 'evaluative thinking' to help CD program coordinators and practitioners question and rethink their assumptions and adapt their practices regarding the community context where they work (Archibald et al., 2016).

\subsection{Theories and approaches to RP: Brief overview and conceptualization}


The wide range of academic disciplines and professional practices that engage with RPs, and the "varied experiences of being reflective in practice and research", make difficult to reach a consensus on the concepts and approaches to RPs (Gardner, 2014, p. 18). Theories and approaches to RP are numerous and varied, including: reflective practice and reflexivity theories, postmodernist approaches, critical social theory, psychodynamic or narrative frameworks, and even spirituality and meaning literatures (Ibid, pp. 17-23). In addition, many scholars of RPs also draw from Schön's (1983: 1991) original work to make the distinction between 'reflection-on-action' and 'reflection-in-action'. Reflection-on-action refers to processes of retrospective analysis, interpretation and reconsideration of information, knowledge and recollections of past experiences and events that may lead to new perspectives and patterns of behavior and action (Jasper, 2013, p. 7; Timmins, 2015, p. 113). 'Reflection-in-action', on the other hand, involves a more pro-active process through which practitioners integrate existing and new knowledges and perspectives to modify or adapt their thoughts, actions and responses to situations as they take place (Oelofsen, 2012, pp. 3-4; Timmins, 2015, p. 114).

While examining each of these perspectives in detail is outside the scope and purpose of this paper, we note that most RP framings and approaches converge on the fundamental role of 'experiential learning' (in terms of the ongoing and active reflection of the process of learning, and subsequent meaningful reflection of experience), and the importance of 'generating awareness', in terms of what is meaningful to individuals, (both practitioners and community members) (Boud et al., 2006, p. 158; Gardner, 2014, pp. 35-38; Timmins, 2015, p. 12).

Regarding 'experiential learning', Kolb’s (1984) 4-stage experiential learning cycle (ELC) has been a seminal work within RP circles, consisting of the 'concrete experiences' (activities, events, challenges experienced by an individual or group), followed by the 'reflective observation' or reviewing of such experiences, its 'abstract conceptualization' (interpreting the meanings of such experiences), and finally engaging in the 'active experimentation' or planning (where the interpretations, new knowledge and learned lessons from such experiences are applied and tested) (see Jasper, 2013, pp. 3-4; Oelofsen, 2012, pp. 6-10). Later studies in education, social care and nursing have developed further stages to Kolb's seminal ELC model to include fundamental processes such as 'detailed-planning' and 
'debriefing' highlighting the need for an ongoing and active reflection of the process of learning (Timmins, 2015, pp. 61-62).

The second of these, 'generating awareness' becomes possible through the presence of individual and group discussions of complex concepts and the articulation and sharing of tangible and intangible knowledge, experiences, emotions and values related to an individual or group's practice project (Jasper, 2013; Oelofsen, 2012). It is through these formal and informal, planned and unplanned discussions and 'recounting of significant experiences' that actors 'make sense of situations', enhance their self-awareness and develop and share practice-based wisdom and knowledge (Timmins, 2015, p. 117). Here, the process of 'reflection' itself becomes a fundamental step-by-step and thoughtful process that can happen either 'during the experience or by thinking back and analyzing situations later' (Ibid, p. 115). RP also 'allows practitioners to develop a greater self-awareness about the nature and impact of their performance' (Ibid, p. 119).

Finally, through the combination of 'experiential learning' and 'generating awareness', RPs are considered a way to more deeply understand and engage with knowledge and experiences, making explicit the 'underlying connectedness' between the emotions, thoughts, assumptions and values related to such experiences, their context, and the expectation for change following the reflective process (Gardner, 2014, p. 24). Whether exercised retrospectively ('reflection-on-action') or actively ('reflection-in-action'), reflection is also a means to elicit, re-examine and integrate those knowledges, less tangible 'tacit understandings', values and motivations that tend to accumulate from repeated experience, and which can help to improve practices, make sense of and adapt to uncertain and changing situations (Schön, 1983: 1991, p. 61).

Borrowing from the above theories and approaches, and the review works by Timmins (2015, pp. 113122)(2015: 113-122) and Oelofsen (2012, p. 3), in this paper the authors understand RPs as those processes involved in the thoughtful, iterative and critical analysis, reinterpretation and reframing of knowledge, values, motivations and perspectives of past situations and events taking place within practice settings. RPs and processes of reflection can be active or retrospective and can significantly help improve and/or change practices and actions of social change within ID contexts. 


\subsection{Examining RPs through a values-based elicitation approach}

The authors will argue that the context of a facilitated workshop on ethical and moral values-elicitation can serve as a departure to examine RPs processes through the analysis of conversations and patterns of communication that take place during the workshops. The values-based elicitation workshops examined for this research form part of the ongoing WeValue (WV) project, which is described in more detail in the next section.

Values-based elicitation approaches, such as $\mathrm{WV}$, have been used in different contexts and for a wide variety of purposes, ranging from environmental sustainable development education to identification of shared values in civil society organizations in continental Europe, multi-actor settings engaged in international community development and humanitarian work in Mexico, Lebanon, and Hong Kong (Burford et al., 2016; Burford et al., 2013; Podger et al., 2013), and more recently in the context of community-university collaborative research partnerships in the UK (Brigstocke et al., 2017). Work in process includes legacies of the Gross National Happiness program in Bhutan, and values congruence in Chinese multi-national corporations. Values-based elicitation workshops can be used as 'laboratories' to gain various insights, including into reflective processes involved in the development a language of trust and deep mutual understanding essential in the conception, development and implementation of community development activities (Facer \& Pahl, 2017).

A major benefit of using values-based elicitation approaches to examine processes of reflection within community projects lie in that values, beyond their abstract and philosophical principles, are in themselves 'embodied practices' through which people (e.g. community participants, the participant researchers), make use of their senses, emotions and reasoning to consider and reconsider their orientations, perspectives and approaches to the world (Brigstocke et al., 2017, p. 69). Thus, providing an established framework for reflection through a values-based elicitation workshop may present participants with a safe and adaptable space, and one where deep reflections are facilitated. In addition, by acknowledging both the performative (actively informing values, but not neutrally measuring them) and affective aspects of values elicitation processes, values-based elicitation approaches provide a useful space through which to examine the different ways individuals engage in reflection as well as 
how those reflective practices vary at different moments in terms of the varying patterns of thought articulations, reasoning, tensions and semantic negotiations that take place in the context of CD projects and activities.

Finally, the WV values-based approach can be transferable and replicable across different socio-cultural contexts through the localization of pooled value-statements from a shared 'fuzzy framework' previously elicited and collected from other groups (Podger et al., 2016). 


\section{Research methodology and analysis}

\subsection{Research questions and methodological approach}

In this paper, the authors examine the processes shaping RP in the context of CD projects through an exploratory case-study (Yin, 2017) of three COs participating in a values-based elicitation workshop, the WeValue workshop.

While themes and processes to RP are well established (Kolb, 1984; Schön, 1983: 1991) and have been extensively conceptualized and analyzed in recent literatures and review works (Gardner, 2014; Timmins, 2015), the authors have chosen an exploratory approach based on a grounded, data-driven analysis of conversations and interactions amongst the case-study workshop participants to examine the sub-processes of RP. In addition, case-study was deemed appropriate to adapt the research design and data collection to better answer the research questions (Meyer, 2001), while at the same time allowing for their examination and understanding of the processes of reflection within their own context (Baxter \& Jack, 2008). While the COs projects and services are introduced and the potential use of the WV approach for future analyses of RP within CD contexts reflected upon, it is important to emphasize here that the unit of analysis in this study are the patterns of conversations and interactions within the workshops.

\subsection{Data collection and introduction to the WeValue project and case-study COs}

Data for this research study was collected from three WV workshops carried out in collaboration with three community organizations (COs) based in Brighton, UK, during April 2017 (see Table 1 below). Brighton was chosen for convenience as it is near to the university of the researchers and there are many local COs involved in CD work. All workshops had a duration of approximately between two and four hours, and were audio-recorded and transcribed for later analysis with the consent of all participants.

Early in May 2017, the authors contacted several COs based in the Brighton and Hove area via the Community University Partnership Program network at the University of Brighton. Those COs that 
were interested in taking part in the WV workshop got back in touch to arrange a suitable time, date and venue. Without exception, all three COs that took part in this study were in a transformative stage, either experiencing organizational structure changes, searching for new funding streams or reviewing their strategy plans. Their starting point for participating in the workshops was to reflect on 'who they are' and 'what they do'. They felt that the workshop was a good opportunity to talk about their values and how they were being put into action within their organizations. The people who acted as first point of contact for the COs also felt that the outcomes of the workshop could potential feed into strategic planning and developing their communications platforms such as their institutional websites.

Before continuing with the description of the analysis of the data, we introduce the WeValue project and the three COs taking part of this study.

\section{The WeValue project - a brief overview}

The values-based elicitation approach used for this research is the WeValue approach developed and used by some of the authors and other colleagues since 2011 (WeValue project, 2011). The WV approach is the fruition of a two-year EU-funded research and partnership project, the Education for Sustainable Development Indicators (ESDinds) EU-FP7 project in 2009-2011. The EDSinds project original purpose was to develop values-based indicators and assessment tools to evaluate achievements related to core ethical and spiritual values within COs working in education for sustainable development (ESD) projects (ESDins, 2009-2011; Podger et al., 2010). Since then, researchers have further developed and enhanced the WV approach working in close collaboration with diverse partners ranging from COs and community volunteer groups to academia through small businesses and the public sector, contributing to research and work in organizational change (Burford et al., 2016), participatory design and strategic planning (Harder et al., 2013), exploring the contribution of values-based indicators for complex sustainable development goals (Burford et al., 2013; Ribeiro et al., 2016), building evaluation capacity through the development of values-led monitoring and evaluation frameworks (Burford et al., 2013; Podger et al., 2016), and also identifying and assessing legacies of asset-based community 
projects or partnership collaborations (Brigstocke et al., 2017).

The WV workshop structure consists of three main stages through which human values - ethical, moral or spiritual - are elicited, shared, discussed and mapped to produce 'values statements': articulations of values-in-action of what those community groups consider 'meaningful, worthwhile and valuable' to them (Ibid, p. 70). In Stage 1, there is an elicitation process involving material and non-materials resources and techniques (e.g. photos, videos, sound, artefacts, stories, drawing) co-developed by the facilitators and the workshop participants themselves. These methods and resources are adapted according to the needs of the participants and the relevant socio-cultural context where the workshops are carried out. In Stage 2, participants are introduced to additional trigger statements previously articulated by other groups that have participated in the WV approach. Here the purpose is to generate further individual and group thinking and reflection amongst workshop participants on potential unarticulated values that might have escaped during the elicitation stage, rephrasing, discarding and prioritizing them (Ibid). In Stage 3, the workshop participants engage in a collaborative exercise to organize the resulting 'values-based statements' into a framework relating both shared and unshared values.

While the purpose and shape of each WV workshop varies depending on the needs and priorities of each group, the main objective is that by the end of the workshop a new, creative and flexible 'lens' or 'overall frame' is developed through which participants can view their work and identify previously 'intangible' or unspecified, yet fundamentally important concepts, values or motivations.

$C O-A$

CO-A was established in the late 1990s as an Advocacy, Group Work and Training project to support Brighton's LGBT\&Q communities. In 2011 it became an independent charity run by and for LGBTQ+ staff and volunteers offering free, confidential, independent and impartial services such as: advice and information, advocacy, a peer support group program, wellbeing activities and events, a peer mentoring service, an-out-of-hours online chat service and a food and allotment project, and counselling services. 
CO-B is a Christian faith-motivated charity working in Sussex for over a century in partnership with the Diocese of Chichester. It provides emotional and practical support to children and families in need through one-to-one sessions and home visits. CO-B services include: parenting advice, financial advice, encouragement and support to find work, referral to specialist services, accompaniment and attendance to appointments, advocacy, and providing food and clothing where needed. In addition, CO-B offer after school and holiday activities for children, daytime family drop-ins and support groups.

$\mathrm{CO}-\mathrm{C}$

Over the past five years, $\mathrm{CO}-\mathrm{C}$ has been operating as a Brighton based Community Interest Company providing participatory opportunities for people of all abilities and backgrounds to connect through music. CO-C runs various music workshops and projects using stringed instruments: violin, viola \& cello. They also deliver creative music sessions for people living with dementia and adults with learning difficulties, and carers, designed to help people connect, experience and have fun together. CSO's open and inclusive approach aims is to promote wellbeing, confidence, self-expression, cognitive stimulation, and a real sense of community through playing and creating music. The various workshops and activities are also aimed at enabling interpersonal communication and musical skills development.

\subsection{Data analysis}

The three workshops forming part of this exploratory case-study were analyzed through a rigorous thematic analysis (Braun \& Clarke, 2006) using a grounded approach to coding and thematizing of group discussions and conversations which involved three stages of analysis.

First, the authors carried out a preliminary analysis of all three workshops to identify those concepts, words and patterns of conversation that were most prevalent or recurrent. This consisted of listening to the audio-recordings once, taking notes and cross-checking them against the workshop reports and 
observations notes. The purpose of this preliminary exercise was to identify general patterns of conversation where processes of reflection could be observed.

Second, using these preliminary patterns as a departing point, a more detailed and in-depth analysis of the workshops was carried out. This involved the transcription of the audio-recordings and the systematic coding and time-stamping of relevant patterns of interaction and structures where processes of reflection and critical thinking could be observed (e.g. nuances, clarifications, long silences, emphases and emotions, collaborations, disagreements, misunderstandings).

Finally, the resulting themes and sub-themes from the second round of analysis were then discussed and reviewed amongst authors for their consolidation. The resulting final themes were subsequently arranged according to their recurrence (none, some, common, total) and the workshop stage at which they took place: elicitation (Stg1), trigger-statements (Stg2), and mapping-clustering (Stg3). 
Table 1. Data sources used in this study.

\begin{tabular}{|c|c|c|c|c|c|}
\hline Participant COs & $\begin{array}{l}\text { Workshop } \\
\text { date }\end{array}$ & $\begin{array}{l}\text { Workshop } \\
\text { location }\end{array}$ & Workshop length & Workshop participants & $\begin{array}{l}\text { Workshop data available and used for this } \\
\text { paper }\end{array}$ \\
\hline CO-A & April 19, 2017 & $\begin{array}{l}\text { Brighton, City } \\
\text { Centre, UK }\end{array}$ & $\begin{array}{l}\text { Three hours and } \\
40 \text { minutes }\end{array}$ & $\begin{array}{l}14 \text { participants, including: } \\
10 \text { CO-A-Pts, Three RPts, } \\
\text { and the Facilitator. }\end{array}$ & $\begin{array}{l}\text {-Audio-recording and transcriptions } \\
\text {-Facilitator and RPts workshop observation } \\
\text { notes }\end{array}$ \\
\hline CO-B & April 27, 2017 & $\begin{array}{l}\text { Brighton, } \\
\text { Moulsecoomb, } \\
\text { UK }\end{array}$ & $\begin{array}{l}\text { Two hours and } 50 \\
\text { minutes }\end{array}$ & $\begin{array}{l}10 \text { participants, including: } \\
\text { Six CO-B-Pts, Four RPts, } \\
\text { and the Facilitator. }\end{array}$ & $\begin{array}{l}\text {-Audio-recording* and transcriptions } \\
\text {-Facilitator and RPts workshop observation } \\
\text { notes } \\
\text { *audio-recording not available for Stg3 }\end{array}$ \\
\hline $\mathrm{CO}-\mathrm{C}$ & April 28, 2017 & $\begin{array}{l}\text { Brighton, } \\
\text { Moulsecoomb, } \\
\text { UK }\end{array}$ & $\begin{array}{l}\text { Two hours and } 30 \\
\text { minutes }\end{array}$ & $\begin{array}{l}\text { Six participants, including: } \\
\text { Three CO-C-Pts, Two } \\
\text { RPts, and the Facilitator. }\end{array}$ & $\begin{array}{l}\text {-Audio-recording* and transcriptions } \\
\text {-Facilitator and RPts workshop observation } \\
\text { notes } \\
\text { *audio-recording not available for Stg1 }\end{array}$ \\
\hline $\begin{array}{l}\text { Additional data. } \\
\text { Available as }\end{array}$ & \multicolumn{5}{|c|}{$\begin{array}{l}\text { Process documentation reports of al } \\
\text { and final COs' values frameworks. }\end{array}$} \\
\hline
\end{tabular}


supplementary

materials) 


\section{Findings}

\subsection{Emerging themes and sub-themes of RPs}

The thematic analysis of the three WV workshops derived four main grounded themes where processes of reflection were observed: Reasoning, Active listening, Tension, and Collective articulation. Within each of these, several sub-themes were also discerned, and their occurrence mapped (see Table 2 below). The themes and sub-themes emerging from the analysis are first described with examples from the data, and later summarized on a diagram to help visualize their interrelationships. The grounded themes and sub-themes described in this section represent patterns or structures of conversations and instances of interactions amongst workshop participants where processes of reflection were observed.

It is important to note that neither themes nor their respective sub-themes follow a prescribed sequential or linear order, but instead they were often reiterated or found overlapping each other. Furthermore, as the authors carried on with the various rounds of analysis and consolidation of themes and sub-themes, it became evident that themes under 'Reasoning' and 'Active listening' related to reflection processes happening at a personal level and preceding those associated to group reflection identified under 'Group discussions'. The final analysis, however, showed that processes at both personal and group level were feeding each other recurrently. Therefore, while this distinction is depicted in the diagram at the end of the Findings section (Figure 1), the authors decided not to subdivide themes and sub-themes at personal or group levels.

Table 2. Mapping of themes and sub-themes found per workshop and workshop stage.

\begin{tabular}{|l|l|l|l|l|l|l|l|l|l|}
\hline \multicolumn{1}{|c|}{ Stages } & \multicolumn{2}{|l|}{ S1 - Elicitation } & \multicolumn{2}{l|}{ S2 - Trigger-statements } & \multicolumn{2}{c|}{ S3 - Mapping and clustering } \\
\hline Themes & CO-A & CO-B & CO-C & CO-A & CO-B & CO-C & CO-A & CO-B* & CO-C \\
\hline (i) Reasoning & & & & & & & & & \\
\hline \multirow{2}{*}{$\begin{array}{l}\text { a) Justification } \\
\text { b) Articulation } \\
\text { c) Recall }\end{array}$} & $\checkmark \checkmark$ & & & $\checkmark \checkmark$ & $\checkmark$ & $\checkmark \checkmark \checkmark$ & & & \\
\cline { 2 - 11 } & $\checkmark \checkmark$ & $\checkmark \checkmark$ & $\checkmark \checkmark \checkmark$ & $\checkmark \checkmark$ & $\checkmark \checkmark$ & & $\checkmark$ & $\checkmark \checkmark$ & $\checkmark$ \\
\cline { 2 - 10 } & & & $\checkmark$ & $\checkmark$ & $\checkmark$ & & & & \\
\hline
\end{tabular}




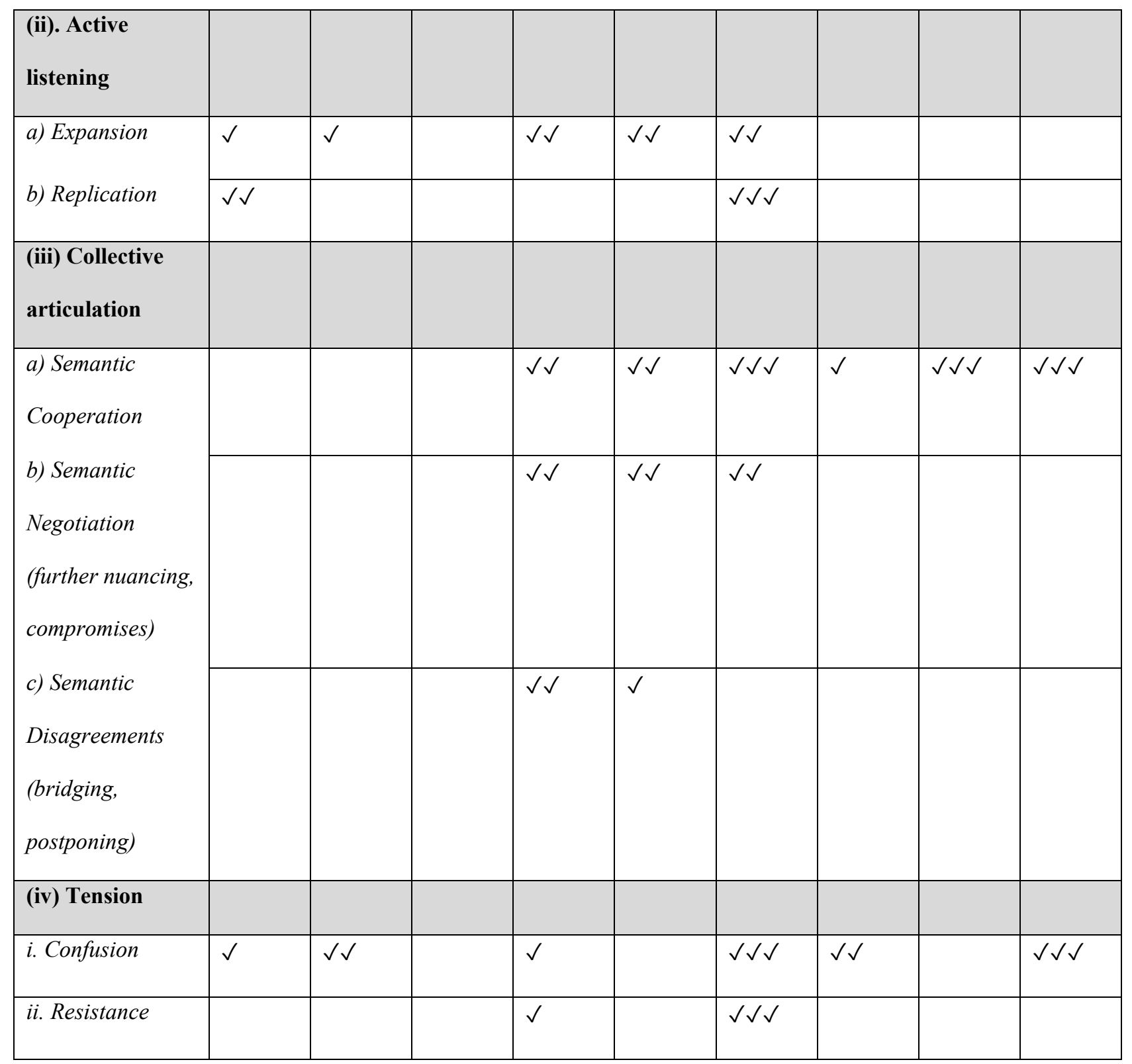

Notes: $($ None $)=$ evidence was not found or was insufficient or inconsistent to substantiate as evidence; $\sqrt{ }($ Some $)=$ less than half the workshop participants involved; $\checkmark \checkmark($ Common $)=$ more than half the workshop participants involved; $\checkmark \checkmark \checkmark$ $($ Total $)=$ all workshop participants involved. $*=$ audio-recording of this section of the workshop is not available, here data is from RPts and Facilitator's observation notes, as well as workshop process documentation. 


\section{(i) Reasoning}

Reasoning was observed both at the elicitation ( $\mathrm{Stg} 1)$ and trigger-statement ( $\mathrm{Stg} 2)$ stages across all workshops, but not at the mapping-clustering (Stg3) stage. Reasoning took place through either one of three main processes: (i) justification, (ii) articulation, and (iii) recall.

\section{a) Justification}

Processes of justification were most common during Stg2, and to a lesser degree in Stg1. Specific instances of justification were observed during $\mathrm{CO}-\mathrm{A}$ and $\mathrm{CO}-\mathrm{C}$ workshops. Here participants were observed presenting and explaining the reasons for their choices of photos in Stg1 or trigger-statements in Stg2. In all cases, when participants opened the presentation of their choices they felt the need to justify them even though this was not immediately required by the facilitator. Participants did so by either describing some very specific aspects of pictures or emphasizing certain words from triggerstatements and sharing the connection they made to their roles within the organization or their motivations to join the organization.

\section{b) Articulation}

Articulation was present throughout all workshops in various forms. It was particularly evident during Stg2 during CO-A and B workshops, and to a lesser degree in Stg3 with CO-B and CO-C. Processes of articulation were observed when participants sought to clarify concepts following questions by the Facilitator and the other participants, or tried to nuance or deepen thoughts or statements by either drawing from personal experiences and anecdotes at work, their understanding of what their organization does or their own recollection of what took place during an event at work.

Justification and articulation were often found directly connected and overlapping when participants sought to clarify or provide more depth to their explanation of choices by ascribing meaning to them. For instance, during Stg1 of the CO-A workshop one of the participants explains their choice of a picture where lights of different colors are reflected on a body of water with ripples, and then ascribes it meaning by describing their role within $\mathrm{CO}-\mathrm{A}$ and sharing their interpretation of CO-A's services: 
'So, this is my pick [...] it's really beautiful, I was drawn to its beauty. Ahm, so, it's obviously a reflection of like- It's got the rainbow colors so that's fairly, an obvious thing for us. And, but for me, just to explain a little bit about my role, I've got a different role to everybody else. I don't directly deliver any services. I'm a Business Development Manager [...] We've been restricted for many years on statutory funding [...] so, I'm building up new ways. So, what's important to me is capturing the impact of the work that [CO-A] does. So, those ripples, there's lots and lots of ripples, and that's for me the impact. And there is something about it being seamless but distinct as well, which is a bit of a, I understand that is a contradiction, but that is what, what our services do. I've always been struck by how this sort of wrap around people of the services of [CO-A]' (CO-A_Pt\#1, Stg1)

Here, for CO-A_Pt\#1 is important to share their reason for picking up the photo with the rainbow colors, aesthetically 'beautiful' and association to CO-A's work an 'obvious thing for us', (justification), while at the same time clarify its meaning by connecting such photo to their role within $\mathrm{CO}-\mathrm{A}$, 'business manager', and their understanding of CO-A's services and their wider social impact; 'lots and lots of ripples', both 'seamless' and 'distinct', coming together to 'wrap up' the service user (articulation).

It was also observed that, in most cases, as the workshop exercises progressed, participants became used to the format of the exercises and became more pre-prepared to justify and articulate their picks in clearer and more concise sentences, sometimes even anticipating the next steps while presenting and communicating their ideas to others.

Finally, processes of justification and articulation were present at the individual and group levels. While articulation at group level is described as a separate theme below, what was a common pattern here was the facilitator's leadership skills in positively managing and encouraging these processes. In fact, when participants got stuck or confused during processes of Reasoning (see 4. Tensions below), the modelling - sharing of personal stories and recalling of past experiences by the facilitator - seemed to enable the processes of justification and articulation at individual and group levels.

\section{c) Recall}


The authors use the term 'recall' to refer to some retrospective thinking where participants, following the choice of a statement by another participant, suddenly remembered an aspect of their jobs or a concept that they had not previously considered. Furthermore, in some examples of the recall process, participants began making connections to other participants' statements or ideas, even if they had not originally engaged in the conversation at all.

The example quote below is from CO-A_Stg2 and shows a moment where both CO-A_Pts\#2 and \#7 are finalizing a value-statement with the facilitator and $\mathrm{Pt} \# 4$, who had not been participating in the conversation, decides to come in and share their story:

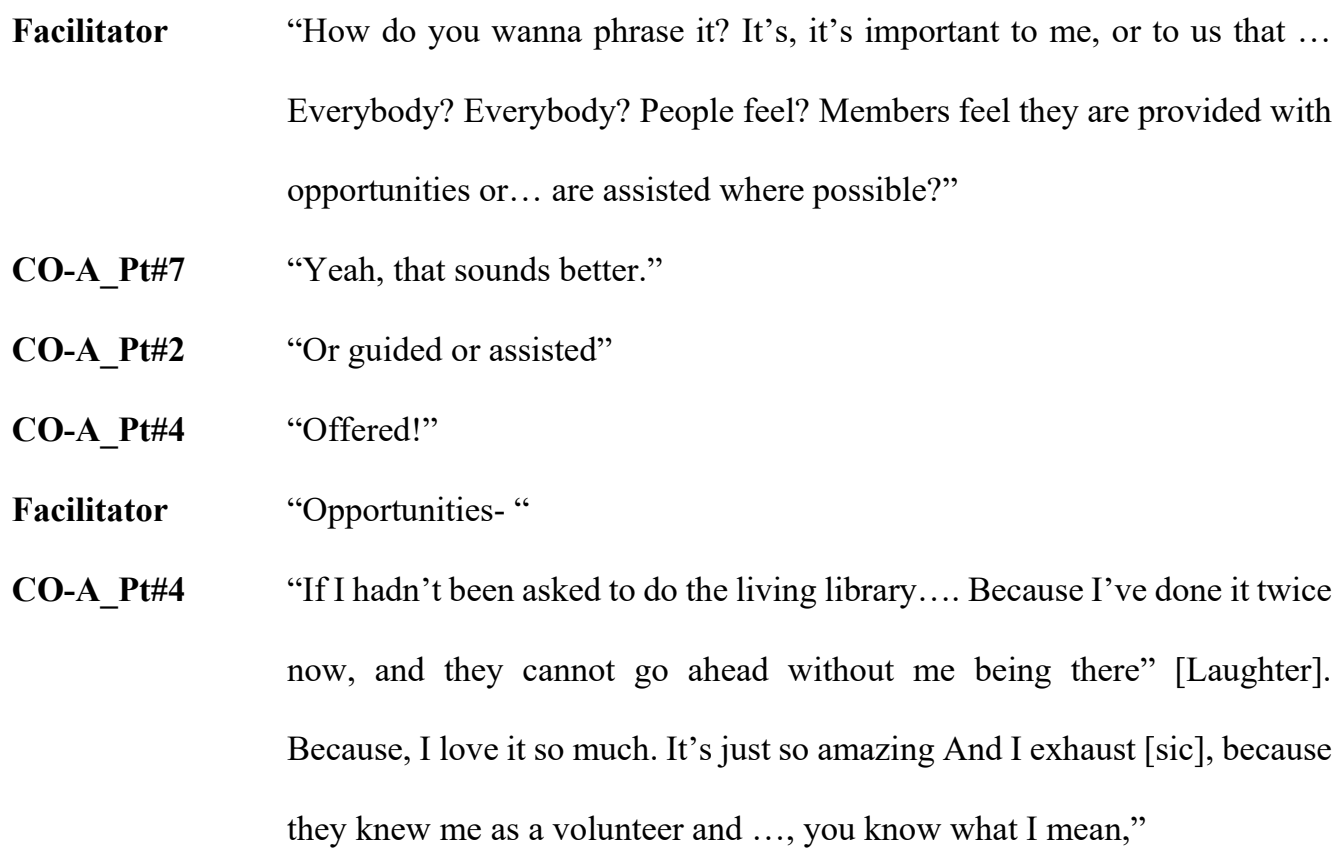

\section{(ii) Active listening}

Active listening (AL) refers to those moments during which participants were observed to build upon or draw from each other's statements to engage in discussions, express opinions and clarify thoughts, or even help others. Processes of AL were identified in terms of (a) expansion, and (b) replication.

\section{a) Expansion}


Expansion was clearly observed in all three workshops during Stg2, and at CO-A and CO-B workshops during Stg1. The example quoted below is from CO-A_Pt\#2 during Stg1:

'[...] I chose the colorful jigsaw picture. And that stood out at me immediately. Even from sat out here, I definitely wanted to go to that one. I'm gonna steal a couple of things you said, [CO-A_Pt\#1], actually. About, firstly about boundaries [...] [It] inspired me what you said there, that 'as an organization we, we are really bounded to our separate [work], but we, we work together as well. So, as a service we can, ... I do feel that the word 'family' comes a lot when I describe [CO-A]. And the idea of the people that visit us being quite isolated, quite often. And fitting everybody sort of fitting together and, and, fitting in, so finding a community of people that are just like you in different kinds of ways. I think that's really important at [CO-A].' (CO-A_Pt\#2, Stg1)

In the above example, while CO-A_Pt\#2 presents their photo, a 'color jigsaw', they draw from COA_Pt\#1's concept of 'boundaries' with regard to the different services and roles within the organization, in order to connect it to their understanding of CO-A as a 'family', 'a community of people that are just like you in different kinds of ways'.

\section{b) Replication}

Replication, observed in terms of similarities in response format, did not occur very often but it was very evident when observed during CO-A_Stg1 and CO-C_Stg2. In the latter, all CO-C participants chose to present their chosen trigger-statements by reading them in full and out loud. In CO-A, COA_Pts\#4-8 were observed using the exact same patterns of presentation: first, explaining their choice of picture by using a metaphor or anecdote from work, and second describing their general understanding of the organization's work regarding such metaphor or anecdote.

\section{(iii) Collective articulation}

Collective articulation takes place when members interact, negotiate and/or expand on what they meant until they formulated value-statements. Whether or not these values-statements were consensually agreed or the result of compromises, they were observed as part of a process of collective articulation. 
This was observed through three main patterns of interaction: (i) semantic cooperation, (ii) semantic negotiation, and (iii) semantic disagreement.

\section{a) Semantic cooperation}

Semantic cooperation was present in all workshops during Stg2, and at CO-A and CO-C workshops during Stg3. During Stg2, semantic cooperation was identified as those processes where participants concurred and supported each other by suggesting words or sharing ideas to aid others articulate, simplify, rephrase, reorder, and/or relate concepts and meanings when engaging with the valuesstatements. Semantic cooperation was very common for CO-A and B, and total for CO-C during Stg2. During Stg3, the process was total in CO-B and C with all participants engaged together in the clustering of values-statements. However, it was partial during CO-A with participants splitting two small groups of two and three people and not necessarily engaging between groups until the very end of the clustering exercise (several other CO-A participants were observed as either remaining silent or while others had to leave the workshop without contributing).

While during Stg2 sematic cooperation was observed through participants aiding each other to articulate and relate meaning to specific values-statements, during Stg3 it was observed specifically at those moments when participants listened to other's explanations and motivations for placing certain values-statements in one position or another on the table. Here, whether collaboration was total or partial, all participants were observed respecting each other's turns and allowing each placement and reordering of the values-statements to be observed. In Stg3, semantic cooperation was also seen when both shared, group values, and those not completely shared by all, individual values, were recognized, included and related within the final overall frame of values-statements.

The long exchange below is an example of semantic cooperation from CO-B workshop during Stg2:

CO-B_Pt\#2 'I picked the one "everyone has their role in the team." I think that's important because whilst we talk about people working independently, working remotely, we are still a team and we can meet each other. ... We wouldn't function without each other.' 
CO-B_Pt\#4 'It's uhm, sorry, is, is the, what was the important part for you? Is it the fact that isn't the word "team" or is it "role"? Because.... Is it that "everyone is a team" and then shares...' $[\ldots]$

CO-B_Pt\#2 'I think that it is that, that everyone has a different role and we help each other. [...] A lot of what we talked about would exclude [James]. He's not interested in policy and...But he has a very valuable part. So, lots of things we do will matter'

CO-B_Pt\#1 'What about 'everyone is a team member'? That sounds quite simple but it's saying that this team is being made up of all its members. Or that 'everybody is a member. Yeah, [James] is a member of the team, we're all-'

CO-B_Pt\#2 'Or, "we are all one team".' CO-B_Pt\#1 'Yes.'

The above example is a section of a longer conversation which shows how the group is engaging with each and working together to figure out what is meant by terms such as 'team' or 'role', and the actual implications of using such terms.

\section{b) Semantic negotiation}

Semantic negotiations were only observed during Stg2 of the workshops and took place when there were differences about how to reword trigger-statements, and by extension the different understanding and connection participants made of those statements regarding the work of their organization. While initially the authors related instances of semantic negotiation to processes where Reasoning or Active listening had been low or difficult, more detailed analysis showed that the relationship was not always causal. Instead, negotiations developed as participants reflected more about their values and shared them with others, giving way to emerging differences in opinion and priorities or even understandings 
about their own same organization's mission and objectives, the recollection of past events or the purposes of current and past projects or services.

Depending on the nature of those negotiations, differences were often resolved through further nuancing of ideas and statements, drawing from Reasoning (articulation) or more Active listening (nuanced expansion), to arrive at a consensus through outspoken affirmations or tacit agreements. In other instances, semantic negotiations were worked out through compromises where participants were seen to 'give up' a difference of opinion upon reflecting on what others had said, not necessarily agreeing but trying to find a common ground to move on with the workshop.

Semantic negotiation was observed, for example, during CO-B_Stg2 workshop where following a lengthy discussion on the meaning of 'independence' in the trigger-statements: “... the messages of the organization or project inspire people to start their own initiatives". Despite having agreed on the wording, when CO-B_Pt\#4 reads it out loud once more, others seem to have thought more deeply about the wording. CO-B_Pt\#2, for instance, was not sure about the word 'independence' in the sentence and its broad connotations but could not think of any other words. CO-B_Pt\#3 was not sure whether 'independence' encompassed the idea of 'self-respect', something which seemed fundamental to them of CO-B's mission to their service users. CO-B_Pt\#4 thought that 'self-respect' had already been captured in the previous value-statement but concurred with CO-B_Pt\#3 in that 'independence sounded too big and impersonal, 'not reflective of the values of our organization.' At the same time, CO-B_Pt\#5 is heard arguing that the word 'independence' should be included. CO-B_Pt\#1 is then heard trying to reach a compromise by throwing in similar concepts like 'self-sufficiency,' 'success', and 'the future' to replace 'independence'. The negotiation is resolved when the group agrees to add the word 'selfrespect' at the beginning while keeping the word 'independence' with its localized connotation to COB context: “... we inspire families to take control of their lives and move towards independence".

The process described above was also observed during $\mathrm{CO}-\mathrm{A}$, and to a lesser extent during $\mathrm{CO}-\mathrm{C}$, often leading to disagreements or tensions within the group (see next sections below). What was important during these exchanges was the facilitator's timely interventions to unstuck or redirect participants to facilitate the conversations. During those moments, the facilitator is recurrently heard drawing 
participants back to reflect on the values-statements in relation to their membership within the organization, identifying those most 'meaningful, valuable and worthwhile' and localizing them (rephrasing, prioritizing, reordering, discarding) not only for the purpose of the workshop exercise, but to also share them with others (colleagues, volunteers, service users) not present at the workshop.

\section{c) Semantic disagreement}

When agreement was not reached through either further nuancing or compromises, negotiations often turned into disagreements. Semantic disagreements were prevalent during the CO-A and CO-B workshops at Stg2, but not during CO-C. Furthermore, agreement or consensus through semantic negotiations did not always mean that differences of opinion and voice within the groups were erased when reaching consensus or agreement. Instead, differences were still much present and often resurfaced with certain words, tones of voice, body gestures or silences participants made when reflecting and engaging with others during the workshop exercises and discussions.

Sometimes differences were irreconcilable, stagnated in vague statements about general social issues or concepts associated to the organization's overall line of work and services, and required the facilitator to draw participants back to the main purpose of the exercise at hand, asking them to make a note of those concepts and postponing them to be able to move one with the workshop, re-introducing them at potentially relevant points in later conversations.

Other times, participants tried bridging disagreements, seeking to reconcile opposite views by drawing back from their previous points and ideas and expanding them. This process differed from that of Active listening examined above in that, while the latter was clearly used to expand someone's point, the former was intended to reconcile a previous idea but not necessarily agree with it. It was observed that when bridging took place, it often diverted from the main conversation that was taking place and created a positive, motivational effect in the mood of some participants.

\section{(iv) Tension}

Processes of semantic negotiation and disagreement, and to a lesser degree Reasoning and Active listening, were characterized by moments where participants became either confused, embarrassed or 
defensive. Processes of tension were identified as moments of (a) confusion and/or (b) resistance, as outlined below.

\section{a) Confusion}

Confusion was observed when in Stg1 CO-A_Pt\#3 struggled trying to relate a photograph to general social issues they understood CO-A to be fighting for, instead of reflecting on what was 'important, meaningful and valuable' to them. Other instances were observed in the transitions between each workshop stage, particularly between Stg1 and Stg2 when participants had to shift from an organic and open task, values elicitation from photographs, to a more reason-based and logical mind-set, reading and localizing trigger-statements.

Confusion generally took place when there was less Active listening (AL) between participants or when some of them were distracted or not paying attention to the Facilitator, as it happened during Stg1 with CO-A_Pt\#3 (see resistance below), or during Stg3 when participants repeatedly felt into extended silences or asked recurrently for explanation to the Facilitator and RPts, this was very common amongst CO-A participants and total with those in CO-C. During those instances, Confusion was initially associated to lack of engagement and low levels of AL.

However, this interrelation between confusion and processes of AL was not causal. During CO-B_Stg2, for example, CO-B_Pt\#3 was unsure of how best to articulate the values that the photographs elicited to them following clear and articulate presentations from two previous participants, CO-B_pts\#1 and \#2. During their presentation, CO-B_Pt\#3 was observed listening to attentively and focused. Confusion in this case did not seem to develop because of lack of AL or focus, but instead CO-B_Pt\#3's pressure to present their thoughts in the same way and depth as the others did. Here, confusion was resolved by the facilitator who proposed to move on with the next participant and get back to CO-B_Pt\#3 at a later stage when they were ready to share.

\section{b) Resistance}

Resistance was only prevalent during Stg2 at the CO-A and CO-C workshops. As shown in the example below during CO-A_Stg2, resistance originated after CO-A_Pt\#3 became confused and uneasy with 
the trigger-statements saying they felt 'like an audit'. The facilitator immediately addresses COA_Pt\#3's concerns using a personal anecdote as example to clarify the meaning and purpose of the trigger-statements, explaining how they were developed in collaboration with former workshop participants from other organizations. RPt\#1 also adds that the statements' purpose is to "provoke a thought" and further reflection amongst participants who can then change and localize the wording of the statements. Despite both facilitator's and RPt\#1's reassurances, and the participant's own acknowledgment, for the remainder of the workshop CO-A_Pt\#3 ceased to actively participate. Only at one other moment in the workshop is CO-A_Pt\#3 heard talking again after being encouraged by COA_Pt\#4 to engage in a group discussion.

The resistance seen in the CO-C workshop was of a different nature. It took place only during Stg2 of the workshop and it arose from the specific type of language and working culture of the organization, not used to work with pre-defined written statements but rather with more creative methods such as music, photographs or artefacts. Resistance in this case was resolved by the Facilitator who proposed participants to abandon the trigger-statements from Stg2 and use those created from scratch by CO-C participants during Stg1. This rapid adaptation was crucial for the workshop facilitation as, from the moment the facilitator switched back to the statements articulated during Stg1, CO-C participants became more relaxed, their tone in conversations more positive, with more moments of laughter, open discussions and reflections leading to constructive suggestions.

CO-C participants' ease to work from images (Stg1) rather than written statements (Stg2), seemed to suggest a strong sensitivity to nuances in language that made the content of the trigger statements inaccessible to them without incorporating local phrasing first. Something that was confirmed by the participants' comments and concerns during the resistance period and its resolution. Paradoxically, it was that same clarity and outspoken resistance to the trigger-statements that allowed the facilitator to identify the problem and rapidly adapt the exercise to suit CO-C participants needs, making the exercise relevant and effective.

When confusion led to a certain opposition from the participants to engage fully or at all in the workshop, the process became one of resistance. Resistance, therefore, was observed as moments 
during the workshops where major confusion or disruptions caused the disengagement, noncooperation, or even unwillingness of participants to participate in discussions and carry on with the workshop exercises.

\subsection{Summarizing the findings}

While processes usually associated to personal or individual reflection (Reasoning and Active listening) often to precede those at a group level (Collective articulation), they often feedback and overlap each other. This overlaps and correlations were most frequently seen when processes of semantic cooperation, negotiations and/or disagreements led to further nuancing, compromises or bridging amongst the participants that trigger more Reasoning and/or AL. Processes identified within Tension (confusion and resistance), were happening throughout the workshops at both personal and group levels. The processes and sub-processes of reflection described above, and their interrelationships, are illustrated in Figure 1 below.

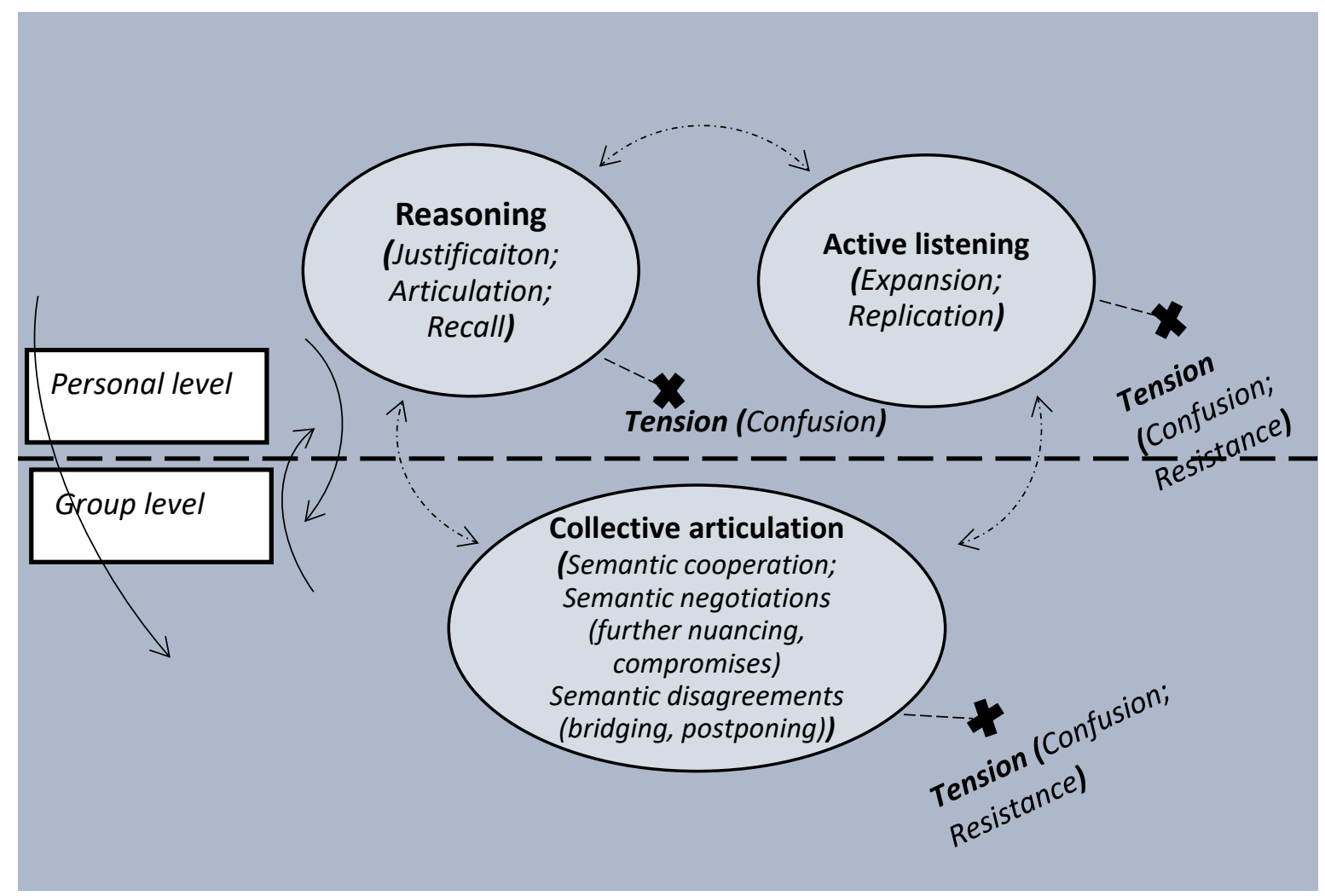


Figure 1. The themes and sub-themes of effective reflexive practices as examined through the three case study workshops, and an indication of their interrelation at the personal and group levels of reflection.

\section{Discussion}

The analysis of the case-study workshops with community organizations has allowed the authors to identify and describe in detail the processes shaping RPs in four grounded themes and related subthemes (shown in Table 1): Reasoning (including sub-themes of justification articulation and recall); Active listening (with sub-themes of expansion and replication); Collective articulation (with subthemes of semantic cooperation, negotiation, and disagreements); and Tensions (with sub-themes of confusion and resistance).

The way in which the processes interrelate confirms the multi-dimensional and non-linear nature of reflection; processes of reflection involve complex and emerging interactions that vary at different levels (individual, group, internal, external) and at the different moments in which those interactions take place (Gardner, 2014, p. 21). The analysis of patterns of conversation and how participants consider and rearticulate their perspectives and values also shows the non-linearity of reflection sub-processes: this challenges the cyclical but ordered process of Kolb's ELC (1984). This is not surprising given the organic, complex and unpredictable nature of community life and CD projects (Neely, 2015; Ramalingam, 2013; Visser, 2010). For theoretical approaches to reflective practice to be most useful to CD research, these should be developed from data and experiences within these contexts. This research is an initial step in this direction.

One of the objectives of the research was to develop an understanding of how RPs happen within CD contexts. Scholars in CD highlight the importance of reflective approaches as process of CD require constant awareness, adaptation and reflection to varying social-cultural contexts (Ife, 2010; Neely, 2015). Furthermore, that all stakeholders need to devote time to critically and actively reflect on their practices, the contexts and factors that shape them, and have the flexibility to adapt to changing circumstances (Fowler \& Ubels, 2010, p. 22; Miller, 2010, p. 23). 
The findings provide some detail on how these processes might happen in a collective or group setting. During the workshop, although individual reflection often preceded those processes at the group level, these were always observed as overlapping and feeding back into one another. These interrelations were most frequently seen when processes of semantic cooperation, negotiation, and/or disagreement led to further nuancing, compromises, or bridging amongst the participants and thus triggered more Reasoning and/or Active Listening from individuals. The authors suggest that carefully creating spaces for individual and group reflection, and allowing iterations between these, might be helpful for developing reflective capacities that can enhance the ability to re-examine and adapt practices in CD. Another suggestion is to place equal importance to rational approaches to reflection as well as embodied and affective processes such as active listening. Another is to have a mechanism in place to introduce moderate dissonance, to stimulate deeper discussions.

The relevance of RPs has also been emphasized in relation to PAR and the need to focus on communities' organizational capacities and developing ownership in the design and implementation of projects (Eade, 2007). The findings support ideas that RPs might contribute to this by allowing values and understandings to become more internalized and embodied (Clarke \& Oswald, 2010, p. 10); and that understanding people's values and motivations for action, and learning from each other's experiences helps better understand situations and facilitates better adaptation to changing circumstances, therefore potentially developing and improving practices (Gardner, 2014, p. 41). This is connected to the joint effects of 'experiential learning' and 'generating awareness' from RP theories; the possibility to more deeply and make explicit less tangible emotions, thoughts and values and interconnectedness between them (Ibid, p. 24).

In addition, the findings point to the importance of language and of listening to how people express their values and motivations. This is most evident in the theme of Collective articulation, and related sub-themes of semantic negotiation, cooperation and disagreements, where participants engaged in group interactions while actively listening to what each other are saying, helping each other make more and more explicit the experiences that shape certain ways of expressing or understanding their actions. 
In the context of increasingly professionalized CD work, as well as the complex nature of the practices involved, it is often easy to assume collective agreement of certain terms and ways of describing what is done. While CD scholars and practitioners recognize the importance of taking time to 'step back', these spaces for collective reflection and discussion would benefit from deep questioning of assumed concepts or implicit collective understandings. The findings show that tensions are important to consider in such discussions and are in fact present throughout the whole process of RP (see Figure 1 above). In the workshops, tensions revealed misunderstandings between participants (confusion) or reactions to the workshop process (resistance), however these appeared to have identifiable origins, such as the different uses of language, discomfort with the activities, or the lack of understanding of the trigger statements. Furthermore, more cooperation did not necessarily mean there was less tension, in other words, tensions were present throughout the workshop stages, and thus can be considered as central to and not limiting or impeding reflective practices.

In this, the authors see a need to examine the role of the facilitator, something already highlighted by Mansuri \& Rao in their World Bank report of over 500 participatory development projects (Mansuri \& Rao, 2013). In this research, the role of the facilitator was evident through their probing of participants, helping provoke deeper thinking and articulation of ideas. For instance, a facilitator's practice-based experience can be used to communicate or clarify concepts during semantic negotiations to connect ideas, enhance processes of recall or even clarify misunderstandings. A more detailed examination of the role of the facilitator within ID contexts could offer an opportunity to understand more clearly the conditions in which certain RPs tools and techniques and approaches to reflection work or are less useful.

Finally, while the findings of this research relate to and complement existing RP theories and approaches introduced at the beginning of this paper, the themes and sub-themes developed from the grounded thematic analysis provide a more fresh and detailed picture of the active skills, interpersonal approaches and practices needed by practitioners and facilitators in CD contexts to allow RPs to happen. There is an opportunity for $\mathrm{CD}$ research to contribute to and expand the understanding of RPs drawing 
on bodies of knowledge on active listening and the role of conflict in group processes (e.g. Jagosh et al., 2015; Putnam, 1994). The authors also suggest that formal or informal processes of reflection should include opportunities for group discussions where semantic cooperation, negotiations and tensions, are allowed a central role.

Here, the findings from the research confirm the usefulness of values-based elicitation and articulation approaches, for opening spaces and opportunities for such elements of reflection. Not only were the WV workshops adapted to the needs of each of the case-study COs, but at least in one occasion (CO-C workshop) they required active listening, ongoing awareness and rapid flexibility by the facilitator to make the process successful. In this sense, the findings, along with the extensive and varied literature of the WV project's diverse applications, certainly demonstrate the adaptability and replicability of values-based elicitation and articulation approaches and their potential to encourage RP in ID contexts.

However, the present research is limited in its scope and exploratory nature and warrants a more detailed examination of how such adaptations and changes occur. Furthermore, it is important to note here that the case-studies examined here represent processes of RPs more likely to be to be used within community groups who have a history of shared experiences, rather than for a variety of shareholders together planning a future ID project. Thus, another item for a future research agenda would be the studies of such groups. There is also the need and opportunity for more longitudinal studies and research collaborations between RP and ID scholarships to identify the factors and circumstances that enhance and obstruct reflection processes in CD projects at different socio-cultural and space-temporal contexts.

\section{Conclusions}

This paper presents an exploratory analysis of three values-based elicitation and articulation workshops with COs based in Brighton, UK, to examine the detailed processes shaping RPs and explore how new insights into RPs might be useful in CD contexts. The use of values-based processes to investigate these 
questions was deemed particularly interesting given their potential to frame RPs around underlying and often implicit understandings rather than assuming shared understanding of practices or terminology.

The analysis of the workshops led the authors to identify four main themes and eleven sub-themes: Reasoning (justification, articulation, recall), Active listening (nuanced expansion, replication), Collective articulation (semantic cooperation, semantic negotiations, semantic disagreements), and Tension (confusion, resistance).

These themes are consistent with those of established RP theories and approaches, however, the analysis offers a more detailed understanding of RPs, and one that is relevant to CD contexts, highlighting the multi-dimensional and non-linear nature of RPs, the importance of productive tensions at all stages of the reflection process, and the need for practitioners to develop certain approaches and skills (such as active listening, working with tensions and group discussions that involve deep semantic negotiations).

When RPs are facilitated, it is valuable to ensure that there is space for both individual and group reflections, and that these can feed into each other. Where such practices happen more informally, to value the interactions between group and individual processes and facilitate interconnections where possible.

The authors recognize the limitations in scope and exploratory nature of the research and see potential for future research to expand on the connections between RPs and CD, through more longitudinal studies, including contexts that involve multiple stakeholder groups without previous shared working experiences. Future world could also further explore the role of tensions in advancing RPs, the role of facilitation, and carry out similar work in developing countries.

Finally, the authors suggest that values-based elicitation and reflection approaches are pertinent within the context of facilitating RP within CD contexts, as these can effectively open spaces for articulating and negotiating complex (and often assumed) meanings, as well as drawing together rational and affective (listening) ways of understanding shared work. 


\section{References}

Aragón, A. O., \& Giles Macedo, J. C. (2010). A 'Systemic Theories of Change' Approach for Purposeful Capacity Development. IDS Bulletin, 41(3), 87-99. doi:10.1111/j.1759-5436.2010.00140.x

Archibald, T., Sharrock, G., Buckley, J., \& Cook, N. (2016). Assumptions, conjectures, and other miracles: The application of evaluative thinking to theory of change models in community development. Evaluation and Program Planning, 59, 119-127. doi:dx.doi.org/10.1016/j.evalprogplan.2016.05.015

Baxter, P., \& Jack, S. (2008). Qualitative case study methodology: Study design and implementation for novice researchers. The qualitative report, 13(4), 544-559.

Boud, D., Cressey, P., \& Docherty, P. (2006). Productive reflection at work: Learning for changing organizations. London: Routledge.

Braun, V., \& Clarke, V. (2006). Using thematic analysis in psychology. Qualitative research in psychology, 3(2), 77-101.

Brigstocke, J., Hoover, E., Harder, M., Graham, P., De Sousa, S., Dearden, A., Light, A., Zamenopoulos, T., Alexiou, K., and Burford, G. (2017). Implicit values: uncounted legacies. In K. Facer \& K. Pahl (Eds.), Valuing interdisciplinary collaborative research: Beyond impact (pp. 65-83). Bristol: Policy Press.

Burford, G., Hoover, E., Stapleton, L., \& Harder, M. K. (2016). An unexpected means of embedding ethics in organizations: Preliminary findings from values-based evaluations. Sustainability, 8(7), 612. doi: doi: 10.3390/su8070612

Burford, G., Hoover, E., Velasco, I., Janoušková, S., Jimenez, A., Piggot, G., Podger, D., and Harder, M. K. (2013). Bringing the "missing pillar" into sustainable development goals: Towards intersubjective values-based indicators. Sustainability, 5(7), 3035-3059. 
Burford, G., Velasco, I., Janoušková, S., Zahradnik, M., Hak, T., Podger, D., Piggot, G., and Harder, M. K. (2013). Field trials of a novel toolkit for evaluating 'intangible'values-related dimensions of projects. Evaluation and Program Planning, 36(1), 1-14.

Burns, D. (2014). Systemic action research: Changing system dynamics to support sustainable change. Action Research, 12(1), 3-18. doi:https://doi.org/10.1177/1476750313513910

Cameron, K. S., \& Quinn, R. E. (2011). Diagnosing and changing organizational culture: Based on the competing values framework: John Wiley \& Sons.

Chevalier, J. M., \& Buckles, D. (2013). Participatory action research: Theory and methods for engaged inquiry. London: Routledge.

Clarke, P., \& Oswald, K. (2010). Introduction: Why Reflect Collectively on Capacities for Change? IDS Bulletin, 41(3), 1-12. doi:10.1111/j.1759-5436.2010.00132.x

Cornwall, A., \& Coelho, V. S. P. (2007). Spaces for change?: the politics of citizen participation in new democratic arenas. London: Zed.

Craig, G. (2010). Community capacity building: Critiquing the concept in different policy contexts. In S. Kenny \& M. Clarke (Eds.), Challenging capacity building: comparative perspectives (pp. 4166). London: Palgrave McMillan.

Eade, D. (2007). Capacity Building: Who Builds Whose Capacity? Development in Practice, 17(4/5), 630-639.

ESDins. (2009-2011). Development of Indicators \& Assessment Tools for CSO Projects Promoting Values-based Education for Sustainable Development (ESDinds). Retrieved from http://blogs.brighton.ac.uk/esdinds/

Facer, K., \& Pahl, K. (2017). Valuing interdisciplinary collaborative research: beyond impact. Bristol: Policy Press.

Fowler, A., \& Ubels, J. (2010). The multi-faceted nature of capacity: two leading frameworks. In J. Ubels, N.-A. Acquaye-Baddoo, \& A. Fowler (Eds.), Capacity development in practice (pp. 1124). London: Earthscan. 
Gardner, F. (2014). Being critically reflective: engaging in holistic practice. Basingstoke, Hampshire: Palgrave Macmillan.

Garrison, D. R. (2015). Thinking collaboratively: Learning in a community of inquiry. London: Routledge.

Gaventa, J. (2006). Finding the spaces for change: A power analysis. IDS Bulletin, 37(6), 23-33. doi:10.1111/j.1759-5436.2006.tb00320.x

Gaventa, J. (2011). Participation Makes A Difference (Vol. 13, pp. 70-76): World Bank.

Gaventa, J., \& Barrett, G. (2010). So What Difference Does it Make? Mapping the Outcomes of Citizen Engagement. IDS Working Papers, 2010(347), 01-72. doi:10.1111/j.20400209.2010.00347_2.x

Harder, M. K., Burford, G., \& Hoover, E. (2013). What is participation? Design leads the way to a cross-disciplinary framework. Design Issues, 29(4), 41-57. doi:https://doi.org/10.1162/DESI_a_00229

Ife, J. (2010). Capacity building and community development. In S. Kenny \& M. Clarke (Eds.), Challenging Capacity Building (pp. 67-84). London: Palgrave McMillan.

Jagosh, J., Bush, P. L., Salsberg, J., Macaulay, A. C., Greenhalgh, T., Wong, G., Cargo, M., Green, L. W., Herbert, C. P., and Pluye, P. (2015). A realist evaluation of community-based participatory research: partnership synergy, trust building and related ripple effects. BMC Public Health, 15(1), 725. doi:10.1186/s12889-015-1949-1

James, R. (2010). Vices and Virtues in Capacity Development by International NGOs. IDS Bulletin, 41(3), 13-24. doi:10.1111/j.1759-5436.2010.00133.x

Jasper, M. (2013). Beginning reflective practice (2nd.ed. ed.). Andover: Cengage Learning.

Kenny, S., \& Clarke, M. (2010). Challenging capacity building: comparative perspectives. London: Palgrave McMillan.

Kolb, D. (1984). Experiential learning as the science of learning and development: Englewood Cliffs, NJ: Prentice Hall. 
Mansuri, G., \& Rao, V. (2013a). Can Participation be Induced? Some evidence from Developing Countries. Critical Review of International Social and Political Philosophy, 16(2), 284.

Mansuri, G., \& Rao, V. (2013b). Localizing Development: Does Participation Work? Retrieved from Washington, D.C.:

McNiff, J. (2013). Action research: Principles and practice. London: Routledge.

Meyer, C. B. (2001). A case in case study methodology. Field methods, 13(4), 329-352.

Miguel, R. M., Elona, H., Gemma, B., Julia, B., \& Thomas, L. (2016). Values as a bridge between sustainability and institutional assessment: A case study from BOKU University. International Journal of Sustainability in Higher Education, 17(1), 40-53. doi:doi:10.1108/IJSHE-12-20140170

Miller, C. (2010). Developing capacities and agency in complex times. In S. Kenny \& M. Clarke (Eds.), Challenging Capacity Building: Comparative Perspectives. (pp. 21-40). London: Palgrave Macmillan.

Millner, N. (2013). Involving Others: From Toolkit to Ethos for a Different Kind of Democracy. In T. Noorani, C. Blencowe, \& C. Brigstoke (Eds.), Problems of Participation: Reflections on Authority, Democracy, and the Struggle for Common Life (pp. 21-36). Lewes, UK: ARN Press.

Moely, B. E., Billig, S. H., \& Holland, B. A. (2009). Creating our identities in servicelearning and community engagement. Charlotte, NC: IAP.

Moore, A. B. (2002). Community Development Practice: Theory in Action. Journal of the Community Development Society, 33(1), 20-32. doi:10.1080/15575330209490140

Moreno, J. M., Noguchi, L. M., \& Harder, M. K. (2017). Understanding the Process of Community Capacity-Building: A Case Study of Two Programs in Yunnan Province, China. World Development, 97, 122-137. doi:http://dx.doi.org/10.1016/j.worlddev.2017.04.005

Neely, K. (2015). Complex adaptive systems as a valid framework for understanding community level development. Development in Practice, 25(6), 785-797.

doi:10.1080/09614524.2015.1060949 
Oelofsen, N. (2012). Developing reflective practice: a guide for students and practitioners of health and social care. Banbury: Lantern.

Podger, D., Hoover, E., Burford, G., Hak, T., \& Harder, M. K. (2016). Revealing values in a complex environmental program: A scaling up of values-based indicators. Journal of Cleaner Production, 134, 225-238.

Podger, D., Piggot, G., Zahradnik, M., Janoušková, S., Velasco, I., Hak, T., Dahl, A., Jimenez, A., and Harder, M. K. (2010). The Earth Charter and the ESDinds Initiative: developing indicators and assessment tools for civil society organisations to examine the values dimensions of sustainability projects. Journal of Education for Sustainable Development, 4(2), 297-305.

Podger, D., Velasco, I., Luna, C. A., Burford, G., \& Harder, M. K. (2013). Can values be measured? Significant contributions from a small civil society organization through action research. Action Research, 11(1), 8-30.

Putnam, L. L. (1994). Productive Conflict: Negotiation as implicit coordination. International Journal of Conflict Management, 5(3), 284-298. doi:doi:10.1108/eb022748

Ramalingam, B. (2013). Aid on the edge of chaos: rethinking international cooperation in a complex world: Oxford University Press.

Schön, D. A. (1983: 1991). The reflective practitioner: how professionals think in action. Aldershot: Ashgate.

Timmins, F. (2015). A-Z of reflective practice. London: Palgrave.

Visser, H. (2010). Capacities at multiple levels and the need for connection: A Bhutan example. In J. Ubels, N.-A. Acquaye-Baddoo, \& A. Fowler (Eds.), Capacity development in practice (pp. 4254). London: Earthscan.

WeValue project, V. (2011). WeValue: A values-based approach. Retrieved from www.wevalue.org Yin, R. K. (2017). Case study research and applications: Design and methods: SAGE Publications. 